\title{
LECTURA Y ORALIDAD EN LA ESCUELA DEL SIGLO XXI. MATERIALES DE ENSEÑANZA PARA LAS PRÁCTICAS DE LENGUA Y LITERATURA EN EL MUNDO DIGITAL ${ }^{1}$
}

\author{
Carolina Tosi \\ Universidad de Buenos Aires (Argentina)
}

\begin{abstract}
RESUMEN: El presente trabajo ofrece un abordaje en torno a la educación lingüística y literaria en el nivel secundario, apelando a los recursos que ofrecen las nuevas tecnologías de la información y la comunicación. En primer lugar, el análisis evidencia que actualmente el rol del docente se ha complejizado, ya que se desempeña como mediador entre los estudiantes, los libros impresos y las prácticas del ámbito digital, a la vez que se posiciona como administrador y guía en el uso de las herramientas virtuales. En este sentido, se caracterizan los recursos digitales como potenciales materiales de enseñanza, haciendo hincapié en los producidos en la Argentina. En tercer lugar, se demuestra la relevancia de géneros y soportes digitales para el abordaje de la práctica de la oralidad en la educación lingüística y literaria. Para ello, y a modo ilustrativo, se ofrece una serie de experiencias pedagógicas bosquejadas en cursos de capacitación para docentes y futuros docentes en la Argentina. Finalmente, y sobre la base de los estudios de Chartier (2015) y Goldsmith (2015), se deja planteado que la reflexión sobre el lenguaje y los estudios literarios se constituyen como un campo de conocimiento en plena "ebullición" y, atento a ello, el aula puede ser un espacio propicio, tanto para los docentes como para los estudiantes, para indagar y participar de esas transformaciones.
\end{abstract}

PALABRAS CLAVE: lectura, recurso digital, literatura, lenguaje, oralidad.

1. Este trabajo forma parte de mi proyecto de investigación "Discursividades escolares del siglo XXI. Un abordaje sobre la configuración enunciativa de los géneros editoriales con destinatario infantil y juvenil y recursos didácticos digitales, en pos de la trasferencia a los ámbitos de la enseñanza y la edición" (CONICET) y del Proyecto FILOCyT 19-047 "Discurso y políticas editoriales en géneros con destinatario infantil y juvenil" (FFyL, UBA), y del proyecto PICT 2018-01830 "Configuraciones discursivas en géneros editoriales con destinatario infantil y juvenil". 


\title{
READING AND ORALITY IN THE $21^{\text {ST }}$ CENTURY SCHOOL. TEACHING MATERIALS FOR LINGUISTIC AND LITERACY EDUCATION IN THE DIGITAL WORLD
}

\begin{abstract}
This paper offers an approach to linguistic and literary education at the secondary level, appealing to the resources offered by new information and communication technologies. In the first place, the analysis shows that currently the teacher's role has become more complex, since he works as a mediator between students, printed books and digital practices, while positioning himself as administrator and guide in the use of virtual tools. In this sense, digital resources are characterized as potential teaching materials, emphasizing those produced in Argentina. Thirdly, the relevance of genres and digital media for the approach to the practice of orality in linguistic and literary education is demonstrated. To do this, and by way of illustration, a series of pedagogical experiences outlined in training courses for teachers and future teachers in Argentina is offered. Finally, and based on the studies of Chartier (2015) and Goldsmith (2015), it is stated that the reflection on language and literary studies are constituted as a field of knowledge in full "boiling" and, attentive to it , the classroom can be a propitious space, both for teachers and students, to investigate and participate in these transformations.
\end{abstract}

KEYWORDS: Reading, digital resource, literature, language, orality.

Recibido: 27/05/2019

Aceptado: 23/10/2019

Correspondencia: Carolina Tosi, UBA-CONICET. Pabellón IFIBYNE, Av. Costanera Rafael Obligado, Buenos Aires, Argentina, CABA 1428. Email: carolinaltosi@gmail.com.

La revolución del texto electrónico es y será también una revolución de la lectura.

Roger Chartier (2015: 2)

\section{INTRODUCCIÓN}

No caben dudas de que las redes y los entornos virtuales han transformado las prácticas lectoras del siglo XXI. Nuevos formatos, géneros e intercambios han incidido en los hábitos y las competencias lectoras, a punto tal de que, desde los estudios la lectura y escritura, se haya hecho imprescindible reconceptualizar el acto y el proceso de leer, así como redefinir el rol del lector en el ámbito digital (Chartier, 2015). ${ }^{2}$

A la par, se modificaron las prácticas docentes. Si bien el libro de texto aún se utiliza en forma masiva para la enseñanza, es usual que los profesores implementen he-

2. En este sentido, Chartier señala los múltiples efectos de la revolución del texto electrónico, entendida como la transformación radical de las modalidades de producción, transmisión y recepción de lo escrito. Para ampliar el tema, consultar Chartier (2015). 
rramientas digitales. En efecto, para preparar un tema o diseñar una clase, los docentes tienen a disposición multiplicidad de materiales en la web, en diferentes formatos, correspondientes a distintos géneros y producidos por diversos actores sociales.

Si se hace referencia específicamente al área de Lengua y Literatura o Prácticas del Lenguaje -como se denomina la materia en la Argentina-, es posible encontrar gran diversidad de materiales en la web: textos académicos, periodísticos, literarios y de divulgación, en diversos formatos, géneros y soportes -escrito, oral, multimedia-.

De lo expuesto hasta aquí devienen dos consecuencias evidentes para la educación lingüística y literaria en la actualidad. Por un lado, el rol del docente se ha complejizado porque necesariamente ejerce como mediador entre sus estudiantes, los libros impresos e internet, y también se posiciona como administrador y guía en el uso de recursos digitales. Por otro lado, las prácticas de enseñanza de la lengua y la literatura se enriquecen a partir del acceso a diferentes soportes que permiten la diversificación de los materiales usados para las propuestas didácticas. Sumado a ello, la incorporación de prácticas novedosas de lectura y de nuevas formas de producir, leer y comentar los textos -pensemos en la fan fiction, en el slam de poesía o en los booktubers $-^{3}$ puede atraer con mayor eficacia a los lectores jóvenes.

A partir de este encuadre, el presente trabajo se propone abordar el uso de materiales digitales para la enseñanza de la lengua y la literatura en el nivel medio o secundario. Con ese fin, indago la producción de materiales en la Argentina y su aplicación en la enseñanza. Para acotar el análisis me referiré al abordaje de la oralidad, una práctica central en los diseños curriculares, pero que ha planteado problemas en la práctica concreta. En efecto, tradicionalmente la escuela ha tenido la dificultad de abordar la fugacidad de lo oral y de disponer de textos orales para trabajar en el aula, pero ahora esto ha cambiado gracias a las nuevas tecnologías (Magadán, 2014). El objetivo, entonces, consiste en mostrar que, mediante el uso de recursos digitales, el docente puede instalar en el aula diversas situaciones comunicativas orales que requieran de una escucha crítica y atenta para lograr la reflexión y el análisis. A modo ilustrativo, presento ejemplos de prácticas didácticas para trabajar la oralidad en el área de Lengua y Literatura, basándome en la experiencia de una serie de talleres de capacitación que impartí a docentes y futuros docentes de nivel secundario, durante 2018 y 2019 en diferentes ciudades de Argentina, en el marco de las acciones de transferencia que realizo ${ }^{4}$.

El trabajo se estructura de la siguiente manera. Primero, caracterizo los recursos digitales como potenciales materiales de enseñanza, haciendo hincapié en los producidos en la Argentina y, en segundo lugar, la relevancia de las redes en construir espacios de lectura, escritura, intercambio y crítica. En tercer lugar, doy cuenta de la importancia de la práctica de la oralidad y presento un abordaje que muestra las

3. En el apartado 3 se caracterizan esos formatos y/o géneros digitales.

4. Algunos de los talleres que dicté, en el marco de mi investigación en CONICET, fueron: "Entre libros de texto y recursos digitales. Los materiales de enseñanza en el aula" (Carrera de Letras, Facultad de Comunicación Social, Ciencias de la Educación y Psicopedagogía. Universidad de Lomas de Zamora, 2019) y "De los libros de texto a los recursos digitales. Características, usos y selección de materiales de enseñanza" (Foro Internacional por el Fomento del Libro y la Lectura en Resistencia, Chaco, Fundación Mempo Giardinelli, 2019). 
diferentes variedades y estilos de la oralidad y su vinculación con la literatura y los estudios del lenguaje. Finalmente, planteo las conclusiones.

\section{LOS RECURSOS DIGITALES COMO MATERIALES DE ENSEÑANZA}

Como es sabido, existe una amplia variedad de materiales bibliográficos utilizados para la enseñanza: desde libros y cuadernillos impresos, como libros de texto, antologías, colecciones escolares de literatura, diccionarios, gramáticas y libros de lectura, hasta materiales novedosos que surgieron con el paradigma digital, por ejemplo, los e-books escolares y los recursos virtuales.

En referencia al paradigma digital, paso a distinguir los e-books escolares de los recursos virtuales.

Los e-books escolares son libros digitales, publicados y distribuidos a través de una plataforma. En muchos casos, se trata de versiones digitales de las propuestas impresas (libros de texto), pero enriquecidas con animaciones, videos, actividades interactivas y enlaces a páginas web (Tosi, 2014). El formato, además, permite que el docente y el alumno personalicen el libro y lo intervengan. Si bien la producción de este tipo de material es incipiente en la Argentina, las editoriales, generalmente multinacionales, elaboran libros digitales interactivos a través de plataformas ya creadas, como Edusfera de Santillana o Conecta Plus de SM.

Debido a los altos costos de producción y mantenimiento, las empresas apuntan a ofrecer este tipo de productos a escuelas privadas de alto poder adquisitivo. De hecho, para que el negocio sea redituable, la plataforma tiene que ser utilizada por una escuela en su totalidad, es decir por todos los cursos de una determinada institución. Las propuestas editoriales suelen disponer, por un lado, de contenidos y acompañamiento al docente, y, por el otro, de software y equipamiento tecnológico. Las ventas de este tipo de producto se realizan vía web y las descargas son controladas, ya que no se pueden copiar de una máquina a otra. Sin dudas, el problema más importante que presenta dicho modelo de negocio es el precio elevado, que limita la adopción de la plataforma.

Por otra parte, los recursos digitales son documentos que se desarrollan en un soporte basado en ciertos sistemas, como discos digitales o redes telemáticas -internet o intranet- (Area Moreira, 2004). En relación con internet, Adell (2004) sostiene que la red puede funcionar como biblioteca, imprenta y canal de comunicación. En efecto, en internet, encontramos un gran acervo de materiales digitales (biblioteca), que podemos bajar, compartir y utilizar (imprenta) y comunicarnos masivamente con colegas, especialistas, instituciones, organizaciones y empresas de todo el mundo (canal de comunicación). En este sentido, el docente tiene a disposición en internet una infinita biblioteca de materiales digitales de acceso libre y gratuito que tienen una serie de atributos. Son multimediales, es decir combinan e integran de diversos medios y tipos de información, textual, icónica, sonora, animados, audiovisuales, etc.; flexibles, pues pueden proponer distintos itinerarios de acceso y lectura; interactivos, en la medida en que los usuarios de los materiales pueden comunicarse por diferentes medios (chat, mail, redes sociales, etc.) e hipertextuales, ya que disponen de enlaces para su conexión con diferentes documentos. 
Como es evidente, los recursos digitales tienen amplias ventajas, pero para que puedan constituirse como materiales didácticos el docente debe realizar una serie de acciones previas, pues la elección tiene que estar sujeta a criterios didácticos. En vistas a ello, primero habrá que diseñar una secuencia didáctica, fijar los contenidos y luego elegir los recursos bibliográficos y/o digitales adecuados. De allí se desprende que los recursos digitales se transforman en materiales de enseñanza solo a partir de la selección, diseño y planificación docentes, en pos de una finalidad pedagógica. Dicho de otro modo, el recurso debe estar al servicio de la clase y no al revés, por ejemplo, la razón de utilizar determinado programa debe ser didáctica y no la mera pretensión de usar una herramienta innovadora en la clase. A su vez, es recomendable que el docente les enseñe los criterios de búsqueda y selección a los alumnos: cuáles son las páginas web especializadas, reconocidas y confiables.

\section{Los ReCursos digitales de Lengua y Literatura Para el docente}

El paradigma digital ofrece una serie de recursos específicos para acompañar al docente en el abordaje de la lengua y la literatura en el aula, en general, y de la literatura infantil y juvenil (LIJ), en particular. Entre las propuestas generadas por el Estado argentino -especialmente desde 2003 a 2105- se encuentran diferentes portales que ofrecen variados materiales de LIJ, por ejemplo, el Plan de Lectura (http://planlectura.educ.ar) que dispone de recursos literarios, pedagógicos y audiovisuales, entre los que se destacan libros de acceso libre y gratuito de literatura general y LIJ argentina para descargar, o el canal infantil Paka Paka (http://www.pakapaka.gob.ar/), que cuenta con materiales audiovisuales de y sobre LIJ. Además, se destaca el Portal educ.ar (https://www.educ. ar/recursos), sitio con contenidos, plataforma de formación a distancia y otros servicios del ámbito digital, destinados a docentes, alumnos, familias, directivos, investigadores y organizaciones, que brinda materiales gratuitos y pueden buscarse a través de diferentes criterios: por tipo de recursos (actividades, aplicaciones, efemérides, infografías, mapas, juegos, webquest, etc.) o bien a partir del formato (audio, colecciones, enlaces, galería de imágenes, libro electrónico, recurso interactivo, audiolibro software y video). En el apartado 4, voy a referirme especialmente a la utilización de audiolibros.

Por otra parte, vale destacar que el ámbito digital ha logrado dar visibilidad a la LIJ. Allí, la escritura, la lectura y la crítica de LIJ han encontrado un espacio fértil, de amplia circulación. Existen formatos y géneros literarios innovadores, por ejemplo, blogs y webs de autores y editoriales; clubes de lectura on line; recomendaciones de booktubers, que ofrecen reseñas orales de libros; revistas de literatura digital; ciberpoesía o videopoesía, esto es la plasmación a través de un video con texto, sonido e imágenes ${ }^{5}$; fan fiction, que consiste en una ficción que parte de un texto original o persona famosa y es que creada por y para fans ${ }^{6}$; audiolibros, entendida como la

5. La video-poesía "entra en consonancia con las nuevas manifestaciones de la poesía on line, creadas a través de aplicaciones o programas informáticos que, al mismo tiempo, pueden convertir a los lectores en creadores de textos poéticos en formato digital" (Quiles, 2016: 10). Para ampliar el tema, consultar Quiles (2016).

6. Respecto del fenómeno de la fan fiction tengamos en cuenta que: "La formación de una comunidad inmensa que lee libros impresos y digitales, que comparten opiniones y producciones, puede ir más allá de la determinación mercantil. Un ejemplo ilustrador: los fan fictions. Estos relatos de ficción escritos por fanáticos que utilizan 
grabación en forma oral de un texto; sitios de slam de poesía, es decir un torneo de poesía en el que los participantes se enfrentan a través de recitales dramatizados; aplicaciones como Wattpad (una comunidad de lectores y escritores), que permite publicar, leer y comentar textos, etc. Entre las revistas digitales, es posible señalar a Imaginaria, El Mangrullo, Cultura LIJ. En cuanto a la presencia de la LIJ en los periódicos, esta es muy escasa y solo hay algunas secciones específicas, como "¿Qué vas a leer con tu hijo esta noche?" a cargo de Natalia Blanc (Diario La Nación), y "\#LIJenInfobae" escrita por Julieta Botto y Daniela Azulay (Diario Infobae).

En cambio, en los blogs y páginas especializadas sobre LIJ $^{7}$, la crítica literaria cuenta con un mayor espacio y relevancia. Sus autores se dirigen a los mediadores de lectura (docentes, bibliotecarios, madres y padres) y definen criterios de selección y lectura precisos, que incluyen definiciones de la LIJ, fijan un canon de autores y explican la importancia de este tipo de literatura (en contraposición a las representaciones más extendidas sobre ella que la delimitan como un género literario menor), qué es lo que se espera (función estética) y no de ella (educación en valores, fines éticos, etc.). A partir de lo expuesto, es posible sostener que la crítica de LIJ en dichos espacios, además de ofrecer un juicio de valor sobre una determinada obra, tiene la función de formar y de instruir a una amplia diversidad de mediadores en un área en pleno auge y expansión, como lo es la LIJ (Tosi, 2015). Estos especialistas, entonces, delimitan el campo, contribuyen a fijar un canon de autores y editoriales y modelan determinadas figuras del lector.

Finalmente, no podemos dejar de mencionar a los booktubers o booktriller, jóvenes que recomiendan libros desde sus canales de Youtube y tienen una gran influencia en los jóvenes ${ }^{8}$. Se hallan:

plataformas diversas que se han establecido como nuevos espacios privilegiados de mediación, como los canales de Youtube, donde han surgido los llamados booktriler o bibliotriler, por ejemplo, un género discursivo de mediación que está haciendo más corto el camino entre los jóvenes y la lectura, trasladando un recurso de la publicidad del cine a la publicidad de las obras literarias (Quiles Cabrera, Campos Fernández-Fígares y Martos García 2017: 2).

Al respecto, no hay que soslayar que la lectura de los libros infantiles juveniles ha aumentado a partir del desarrollo de las redes sociales, los booktubers y las plataformas de lectura. Como puede apreciarse, los recursos digitales trazaron un camino antes impensado, que conduce de las pantallas a los libros; como sostiene Sáez: "El desarrollo tecnológico significó un puente para muchos jóvenes hacia los libros" (Sáez, 2019: 7). De ahí se desprende que los chicos leen (y mucho) y, además,

personajes y ambientes de otra obra emergen de sitios web autónomos y ponen en tensión la noción de autor y, por ende, de derechos y regalías editoriales. Por ejemplo, J.K. Rowlling tuvo que aceptar que cientos de fan fiction inspirados en Harry Potter modificaran la historia y continuaran una saga que se daba por cerrada" (Sáez, 2019: 5).

7. Los de mayor circulación son: https://quijotesyquijotinas2.wordpress.com/, http://www. dondevivenloslibros.com/, http://www.blogs.buenosaires.gov.ar/librodearena/, http://romanba1.blogspot. com/, http://espaciodelij.blogspot.com/, http://julianaseditoras.blogspot.com/, http://avionqueva.com/ y http://lij-jg.blogspot.com/

8. En la Argentina, se destacan los booktubers Leonel Teti, Federico Valotta, Matías G.B. del blog "Cenizas de Papel", Maca Yanelli, Naty Bustamente, Anto Tomando y Calu Dente, entre otros. 
consumen crítica literaria, pero lo hacen a través de vías no tradicionales. Por eso es necesario que los mediadores tengan en cuenta también estos espacios virtuales para aprovecharlos y utilizarlos también como recursos didácticos para sus clases.

Habiendo esbozado un panorama de los materiales digitales, especialmente en la Argentina, en los próximos apartados me detendré en algunos de ellos para plantear el abordaje de la oralidad en el aula y proponerlos como recursos educativos de enseñanza.

\section{LA ORALIDAD EN LOS DISEÑOS CURRICULARES ARGENTINOS}

Según los diseños curriculares de la Argentina, tanto los correspondientes a la escuela primaria como a la secundaria, se le asigna un lugar predominante a la oralidad. En efecto, los documentos curriculares argentinos coinciden en que si hay un lugar donde se hace claramente perceptible la dimensión social del lenguaje es en la oralidad. Atento a ello, su abordaje requiere de una minuciosa observación de la variedad de manifestaciones que la constituyen. Sin dudas, no se puede sostener que haya una "oralidad correcta", sino solo variaciones que dependen de los géneros, las situaciones comunicativas, los participantes, etc. Así, los diseños curriculares consideran que el aprendizaje de las prácticas orales del lenguaje implica el desempeño de los alumnos en situaciones de uso que requieren de la utilización de estrategias y recursos elaborados que les permitan interactuar eficazmente con variedad de formatos de distinta complejidad en los ámbitos escolares y sociales. En esta línea, las nuevas tecnologías pueden ayudar a que los estudiantes accedan a diferentes formatos de discursos orales y pongan "en oralidad" diversos discursos, apelando a ciertas herramientas y según los propósitos trazados.

En lo que sigue, a modo ejemplar -y teniendo en cuenta el espacio acotado que exige una publicación de este tipo-, presentaré solo tres recursos digitales: 1) los audiolibros, para trabajar la oralidad literaria, 2) la ponencia leída y 3) el spot divulgativo, ambos con el fin de analizar discursos orales de especialistas. Por un lado, se escogieron los audiolibros, que se constituyen como un soporte de literatura novedoso y de fácil acceso (suelen encontrarse en portales educativos en forma libre y gratuita), aunque, generalmente, no han sido objeto de estudio por parte de los investigadores de los campos de Educación y Literatura. Por otro lado, se pretendió establecer vínculos entre el ámbito académico y literario y trabajar dos géneros, como la ponencia leída y el spot divulgativo, que pueden fomentar el debate, la escritura argumentativa y creativa. Se trata de experiencias que, como se mencionó en la introducción, fueron puestas en práctica en diferentes instancias de capacitación que impartí a estudiantes universitarios (futuros docentes) y docentes de nivel secundario, con el fin de promover el uso de las nuevas tecnologías para el diseño de secuencias didácticas.

\subsection{La oralidad y la educación literaria. Los audiolibros}

Educar, el portal educativo del Ministerio de Educación de la Argentina, según ya se explicó, es un sitio de acceso libre y gratuito con contenidos, plataforma de formación a distancia y demás servicios digitales. Asimismo, el portal dispone de un gran acervo bibliográfico digitalizado, en el que se encuentra la colección Lecturas Grabadas que incluye audiolibros. La novedad del audiolibro permite la integración 
de otro sistema de representación del texto literario: el discurso ya no es escrito, sino oral. Llegados a este punto, es necesario precisar que el audiolibro se puede definir como la grabación del contenido de una obra narrada en voz alta por un narrador especializado. Si bien se trata de una herramienta de uso habitual en las clases de Lengua extranjera, hace relativamente poco que se está implementando en las clases de Lengua y Literatura en español. El audiolibro, entonces, presenta un soporte diferente de literatura. No hay que ver. Hay que escuchar. En este sentido, esta práctica puede ser un desafío para cualquier lector y, tal vez un poco más, para el adolescente que está habituado a los productos audiovisuales. Pero, sin dudas, la experiencia puede ser muy enriquecedora, pues el que oye la narración apela a su atención, despliega diferentes estrategias de escucha y potencia su imaginación. En efecto,

El silencio circundante, carente de elementos distractivos, hace que los estudiantes estén dispuestos a transportarse al mundo que propone el libro a partir de la utilización del oído como sentido primario, algo inusual en su rutina diaria. Deberán esforzarse en poner la imaginación en marcha para ver las descripciones de vivos colores a las que el libro alude o representarse los estados de ánimo de los personajes sin verlos actuar de modo directo en una pantalla. (Ministerio de Educación de la Nación, Lecturas Grabadas Docentes, 2010: 8).

Destinado al uso en la escuela secundaria, Lecturas Grabadas se halla en la pestaña "Docentes / Recursos" y consiste en treinta y dos cuentos y una novela breve -de autores reconocidos, mayormente argentinos- en el doble soporte de texto escrito y audio (cf. 1 y 2).

(1) Colección de Lecturas Grabadas.

[글 Mis contenidos $\mathcal{O}$ Me gusta $\alpha_{0}^{0}$ compartir

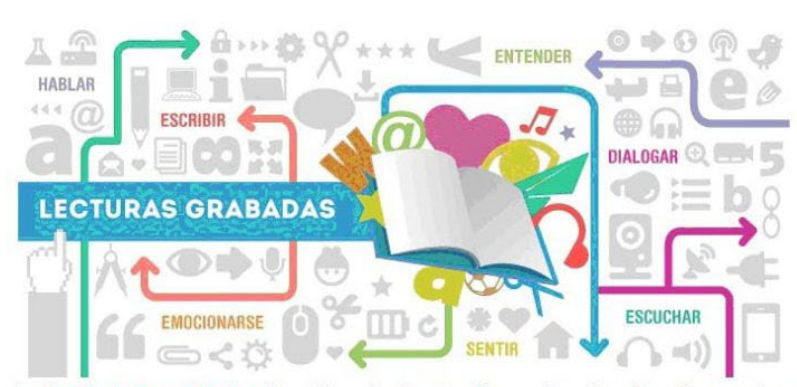

La colección el ecturas Grabadas disponible aqui en formato pdf y en archivos de audio, está compuesta por cuentos de reconocidos escritores argentinos y latinoamericanos. El material se ha seleccionado en función de lograr un acercamiento gozoso a la obra literaria de autores argentinos y latinoamericanos que, por su estética, su musicalidad, su temática y sus proyecciones culturales ayude a recuperar el valor decisivo, poderoso y necesario de la palabra en el aula. Palabras con peso, que signifiquen, que cuestionen, que emocionen, que permitan escuchar, leer, sentir, dialogar y, por sobre todo, pensar.

Para empezar, hacé clic en cualquiera de los enlaces de la sección Recorrer la colección, a la derecha de la pantalla.
$M-Z$

Contenido relacionado

Washington Cucurto:

entrevista cartonera

Ficha del recurso

Nivel: Primaria Secundaria

Área: Lengua Lenguă

Literatura

Disciplina: Literatura

Reflexión sobre la lengua comunicaciön escatita

Tipo de recurso: Uteratura

Tipo de formato: Colección

Etiquetas:

uis Borges Hortalidad jorg:

iteratura argentina Quiroge

enseñanza de literatura didáctica de la literatura Cortázar audiolibro 
(2)

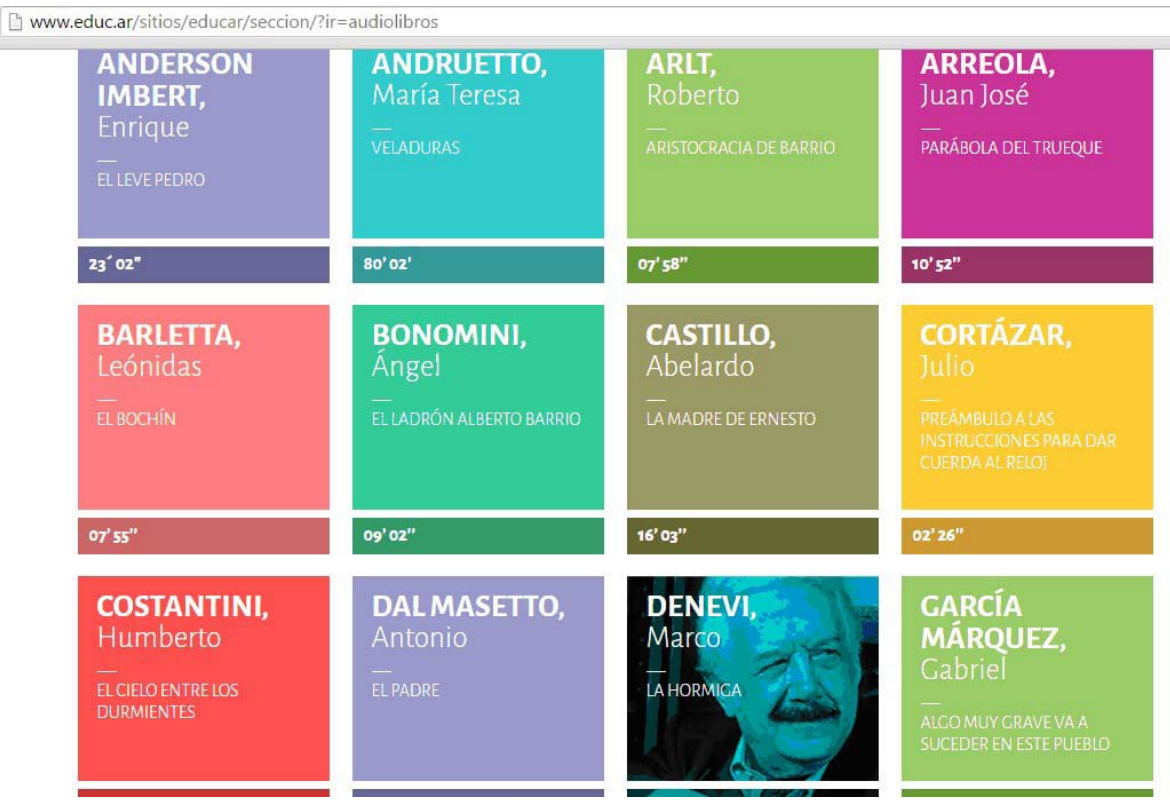

Según afirman Marchetti y Valente (2016: 165), los audiolibros proporcionan al usuario "nuevas maneras de recibir, interpretar y compartir literatura" (Marchetti y Valente, 2016: 165) y modos novedosos de "establecer relaciones con la tradición oral" (Magadán, 2014: 291). De este modo, los audiolibros pueden constituir una herramienta que contribuye a la mediación lectora y permiten abordar la oralidad en las clases de Lengua, una dimensión que solía plantear ciertas dificultades concretas. Al respecto, Magadán (2014: 2) sostiene:

En nuestras clases de Lengua, trabajamos algunos aspectos de la materialidad de la voz: la entonación, las pausas, los acentos (en la enseñanza de lenguas extranjeras, estas prácticas son aún más frecuentes). Pero, para llevar adelante este trabajo con la voz, nos topábamos hasta hace poco con una dificultad: cómo capturar la fugacidad de lo oral. Es el género en otro soporte. Se producen cambios. Las tecnologías hoy nos habilitan, afortunadamente, para hacerlo.

Tal como comenta Magadan (2014: 311), los audiolibros son recursos valiosos "para abordar con los alumnos el análisis de sus diferentes gramáticas y para explorar sus formas de construir sentidos mediante múltiples representaciones sonoras (música, efectos de sonido, voces, entre otros)". El uso de los audiolibros es muy sencillo:

Una netbook y dos parlantes, o un simple reproductor, hacen realidad la transmisión de esta voz. Además, las lecturas grabadas pueden guardarse en las computadoras, facilitando así que los estudiantes escuchen los textos en 
sus casas para mejorar la comprensión, pudiendo volver atrás como se hace con las páginas de un libro. (Ministerio de Educación de la Nación, Lecturas Grabadas Docentes, 2010: 9).

En Lecturas Grabadas, cada obra está acompañada de un material destinado al docente para aplicarlo en la clase: "Bibliografía complementaria del autor y su obra", que a su vez contiene cuatro apartados. Los dos primeros, "Breve reseña para el docente" y "Presentación del cuento a los estudiantes", buscan auxiliar al docente en la preparación de la clase; en este caso del texto de LIJ "Lila y las luces", de Silvia Iparraguirre. Las siguientes secciones "Datos sobre el autor" y "Enlaces" brindan información respecto del autor y sugieren bibliografía relacionada para preparar la secuencia didáctica (cf. 3).

(3) Lila y las luces, de Sylvia Iparraguirre.

\footnotetext{
www.educ.ar/sitios/educar/recursos/ver?id=124622

Portada | Efemérides | Especiales | Visitado por | Juegos
}

\section{«Lila y las luces» de Sylvia Iparraguirre}

Se encuentra aquí disponible el relato, tanto en archivo de texto como en audio.

Asimismo, se ofrece una ficha con información sobre el autor, su obra y algunos enlaces sugeridos.

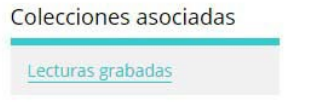

\section{Ficha del recurso}

Nivel: Secundaria

Área: Literatura

Disciplina: Argentina

Tipo de recurso: Literatura

Tipo de formato: Audic

Etiquetas: audiolibro Lecturas

grabadas

Autor/es: Educ.ar

Idioma/s: Español

Fecha de publicación:

19/03/2015

Editor: Educ.ar

Además, la propuesta cuenta con un cuadernillo docente que, en primera instancia, contiene una introducción que explica la organización de la colección y la importancia del trabajo con la oralidad y, luego, hace hincapié en las acciones de leer, escuchar y conversar en la clase de Literatura a través de la experiencia de una docente.

En la misma guía se define al docente como "ensayista", en tanto puede "saber", "dudar", "intuir", "descubrir", "desconocer": "Nos gusta la imagen del docente como ensayista, que trasciende lo que sabe para descubrir lo que no sabe, o para descubrir que no sabe, y a su vez aprender mientras enseña" (2015: 14). 
Por un lado, el trabajo con los audiolibros permite, en términos generales, abordar la comprensión y producción de textos orales y, de modo más específico, cotejar recursos y características con la versión escrita del relato. Por ejemplo, en uno de los talleres, leímos el original impreso Lila y las luces de Silvia Iparraguirre, luego escuchamos el audiolibro y comparamos ambas versiones. Posteriormente, se hicieron grabaciones de anécdotas escolares, a apropósito del contenido de este relato.

Por otro lado, la escucha y abordaje del audiolibro puede llevar a indagar y producir literatura en otros soportes. El docente, entonces, puede ofrecerles a los estudiantes narraciones audiovisuales, de modo que pueda motivar la comparación de los recursos de la narración literaria escrita, oral y audiovisual. Eso hicimos, por ejemplo, en uno de los talleres con el cuento "Un almohadón de plumas", de Horacio Quiroga. Luego de leer el texto original y escuchar el audiolibro, vimos un cortometraje chileno que versionaba el relato ${ }^{9}$. Finalmente, les propuse a los estudiantes que, divididos en grupos, escribieran una experiencia de terror que, en una siguiente instancia, fue versionada en forma oral o audiovisual, recurriendo a Audacity, Windows Movie Maker o Cheese, entre otros programas.

Estas propuestas resultaron novedosas e innovadoras en los talleres dictados, pues consistían en presentar diferentes vías de acceso para leer, oír, mirar, disfrutar y sentir un texto. Simplemente, nos centramos en pensar "una nueva forma de entender lo literario a partir de las posibilidades tecnológicas abiertas por el desarrollo tecnológico digital" (Morales Sánchez, 2014).

\subsection{La oralidad y la educación lingüística. Discursos de especialistas}

La confección de la propuesta del presente apartado se rigió por la pretensión de poner en contacto a los estudiantes con discursos orales de especialistas. Guiados por los objetivos de abordar las características de los géneros orales -que en general son escasamente indagados en la escuela- y propiciar la producción escrita y oral, en lo que sigue se plantea la observación y escucha de videos que tratan el lenguaje inclusivo, un tema de amplio interés y circulación social, producidos por intelectuales, tanto científicos como escritores.

A modo de ejemplo, presento la propuesta trabajada en uno de los talleres de referencia y muestro una serie de producciones de alumnos de secundario realizadas a partir de la puesta en práctica de una docente ${ }^{10}$. El eje temático elegido es el lenguaje inclusivo, cuyo tratamiento desencadena acalorados debates y tiene gran repercusión en los países hispanohablantes. Específicamente, en la Argentina, el tema se instaló en 2018 en el marco del Proyecto de Ley de Interrupción Voluntaria del Embarazo ${ }^{11}$.

9. Cuento de terror del escritor Horacio Quiroga, escrito en 1917, y que fue publicado en el libro Cuentos de amor, de locura y de muerte. La versión cinematográfica corresponde al director Hugo Covarubia y fue realizada con la técnica stop motion en 2007.

10. Leticia Baico, docente de Lengua y Literatura de 4to. año del secundario del Instituto Vocacional Argentino (IVA), de la Ciudad de Buenos Aires (Argentina).

11. En la Argentina, durante 2018, se trató el Proyecto de Ley de Interrupción Voluntaria del Embarazo, que implicaba el derecho al aborto legal, seguro y gratuito. Este proyecto no fue aprobado y, actual- 
En gran parte de los discursos militantes a favor del aborto legal, seguro y gratuito -muchos de los sectores más jóvenes- destacaba el uso del morfema -e como nueva marca de género. Como he dejado sentado en un trabajo anterior (Tosi, 2019), el lenguaje inclusivo puede concebirse como un tema que propicia la reflexión lingüística y el respeto por la diversidad. Comentar, informarse y opinar sobre el tema puede abrir espacios de debate y discusión que habilitan pensar sobre diversas tensiones: la normativa y la trasgresión, la uniformidad y la diversidad, la permanencia y los cambios, etcétera.

Se eligió dicho tema, porque es de interés para el público adolescente y joven, y habilita un hecho único: pensar, reflexionar y tomar posición sobre el lenguaje, sentirlo propio, ya que

El lenguaje que solemos usar parece sernos ajeno, como si constituyera un conjunto de fórmulas prestadas para simplemente desempeñarnos en la calle, en el trabajo, en el aula el abordaje de los textos a modo de una conversación serena y libre, lleva invariablemente a los fenómenos culturales, pero también a los hechos gramaticales (Ministerio de Educación de la Nación, Lecturas Grabadas Docentes, 2010: 15).

Por un lado, utilicé un "spot divulgativo" producido por Filo.news y alojado en https://www.youtube.com/watch?v=8z-uPySZOhY. Allí, Eduardo Bonnin, lingüista e investigador del Consejo Nacional de Investigaciones Científicas y Técnicas (Conicet), explica el fenómeno del lenguaje inclusivo y argumenta sobre su uso. Su destinatario es un público lego, es decir no especialista. Apela a diversos recursos explicativos y argumentativos, como definiciones, comparaciones y analogías, para explicar qué es el lenguaje inclusivo y defender su relevancia. Al tratarse de un género audiovisual, en la construcción del discurso convergen los gestos, la actitud corporal, los planos de la cámara, el diseño gráfico, los graff o subtítulos.

Por otro lado, seleccioné al género "ponencia leída en un congreso" destinado a especialistas o interesados en el tema. Resulta pertinente analizar con los estudiantes las diferencias entre las comunicaciones leídas y las presentaciones orales realizadas, por ejemplo, con soporte audiovisual. Esto puede disparar la reflexión sobre los vínculos entre escritura y oralidad, y su análisis permite comprender que cualquier disertación oral apela o remite a una escritura previa. Para la ocasión, se optó por el discurso de cierre al Congreso de la Lengua Española de 2019, celebrado en Córdoba (Argentina) que pronunció la escritora María Teresa Andruetto y disponible en https://www.lavoz.com.ar/numero-cero/completo-magistral-discurso-de-mariateresa-andruetto-para-cierre-del-congreso-de-lengua. A continuación, se expone un fragmento en el que diserta sobre la literatura y lenguaje inclusivo:

(4) El lenguaje inclusivo nos pone delante de la carga ideológica de la lengua, que habitualmente nos es invisible. Claro que compartimos la lengua y que ella no es de nadie, ni siquiera de las buenas causas.

mente, la interrupción voluntaria del embarazo es ilegal y sigue muriendo gran cantidad de mujeres en abortos precarios. 
Claro que corremos riesgos de que el lenguaje inclusivo se vuelva pura corrección política. Claro que no sabemos qué pasará con la literatura, ni si es posible escribir en lenguaje inclusivo de un modo lo suficientemente cargado de ambigüedad como para conservar la función poética del lenguaje, de un modo que además de hacernos pensar, nos conmueva, nos emocione, nos complejice.

Claro que no sabemos qué sucederá en el largo plazo, si ese lenguaje que viene a irrumpir se estabilizará en la lengua y en tal caso de qué modo, si ingresará y de qué manera a nuestras literaturas, pero sabemos de su uso y expansión en ciertos sectores sociales (especialmente urbanos) y en jóvenes de cualquier género, y vemos cómo impregna y permea los usos públicos, periodísticos y políticos (Discurso de clausura del Congreso Internacional de la Lengua Española, 30/3/2019, en línea).

Se puede abordar la oralidad del discurso de Andruetto teniendo en cuenta diferentes aspectos, por ejemplo, indagar los componentes no lingüísticos (su mirada, los gestos, el tono de la voz o la postura corporal); cómo organizó los momentos de la exposición y argumentación; qué partes no se leyeron y fueron producidas espontáneamente en el discurso y finalmente plantear si la lectura de un texto contribuye a la mejor explicación del disertante.

Llegados a ese punto, es posible plantear una comparación entre los discursos de Bonnin y Andruetto, en función de los géneros, la circulación, los destinatarios, las secuencias explicativas y argumentativas, entre otros aspectos.

Asimismo, a partir de la escucha de estos textos (y de otros que puede proponer el docente), se pueden analizar los argumentos para tomar posturas y generar textos de producción. A modo de ejemplo, se reproducen dos textos argumentativos de alumnos de secundario, en los que exponen su postura ante el uso del lenguaje inclusivo ${ }^{12}$.

(5) En una clase de diecisiete alumnas y un alumno se sigue diciendo "todos" aunque las mujeres sean mayoría. Lo sé porque me pasó a mí. Y cuando algún profesor decía "todas", el único alumno se sentía ofendido, dejado de lado, invisible.

Así nos sentimos todos los días: las mujeres, las personas de género nobinario, neutro o fluido.

La E es una manera de visibilizar. (L.P.)

(6) A mi parecer, el lenguaje inclusivo no se trata solo de cambiar una letra, de cambiar el "masculino" o "femenino" genérico de una palabra y reemplazar su finalidad por la " $E$ ", sino que se trata de generar un cambio cultural y social en el que se visibilice a la mujer y que no se tenga que anteponer la

12. Producciones de un grupo de estudiantes de 4to. año del secundario del Instituto Vocacional Argentino (IVA), de la Ciudad de Buenos Aires (Argentina), generadas por su docente Leticia Baico. Agradezco a lo/as estudiantes Camila Montes de Oca, Lucía Plavnick, Bautista Chevallier, Valentina Rossi, Sofía Enríquez Jiménez y Cecilia Zárate y a su docente, Leticia Baico, por su invalorable colaboración y entusiasmo. 
sexualidad de cualquier persona, pudiendo utilizar palabras como "chiques", "nosotres", "amigues" y "estudiantes", así como también emplear "les" en vez de "los" y "las". Siendo breve y conciso: se trata de insertar a les que no se sientan definides por un sexo predeterminado (lo cual sucede tanto dentro como fuera de la comunidad LGBT) y se trata de pensar en le otre y no solo en une misme. Por eso es bueno hacer un Ilamado de conciencia para implementarlo. (B.C.)

Los estudiantes, según su docente, se manifestaron entusiasmados por el tema y ansiosos por explicar su postura. Para ello, los estudiantes trabajaron en words, hicieron borradores, corrigieron y enviaron los textos por mail. Luego, los textos formaron parte de un debate oral, para el cual los estudiantes tuvieron que indagar sobre las características de este formato y llevarlo a la práctica.

Por otra parte, el análisis de la ponencia de Andruetto puede generar también la producción de otros formatos y géneros. Como se observa en (7) y (8) las estudiantes escribieron relatos utilizando lenguaje inclusivo. Si bien no fue una consigna dada, ellas quisieron llevar a delante la producción para explorar la escritura con estas características discursivas.

\section{(7) $\underline{\text { Confesión }}$}

(Microrrelato)

Un día llegó el profesor refiriéndose a la clase como "todes" y se dieron cuenta de cómo la inclusión era parte del cambio, tanto para los más jóvenes como para los mayores. (C. M. O.)

\section{(8) Un paso adelante si sientes}

Es algo normal que lo adultes traten de divertir a los niñes con juegos, siempre es uno diferente y de vez en cuando se repite uno que otro. Hoy mi maestre eligió un juego un tanto diferente, la consigna era simple: elle redactaba una serie de sentimientos y si nosotres nos sentíamos identificades, teníamos que dar un paso al frente. Antes de decir cualquiera de los sentimientos, repetía lo mismo: "todos los niños que sientan... den un paso al frente" o " todos los chicos que piensan que... den un paso al frente". Pero yo fui la única que no dio ni un paso adelante, porque esperaba a que Ilamen a las chicas, porque yo soy una niña, y le señorite María siempre hablaba de los "chicos", pero yo no me siento como un chico, ¿entonces por qué tenía que dar un paso adelante? Le expliqué esto, pero elle se enojó y me retó, me explicó que cuando habla en masculino, las niñas también entramos en la misma bolsa porque lo usa en términos generales, pero yo no lo logré comprender. (V. R.)

La posterior producción y puesta en común de estos textos permitieron habilitar la reflexión sobre el discurso literario, el género testimonial y la escritura creativa. En este sentido, se puede indagar y discutir en la clase acerca de los efectos de sentido del lenguaje inclusivo en la literatura y cómo afecta la verosimilitud de la historia y las concepciones estéticas. 
Por todo lo expuesto a lo largo de estos apartados, queda demostrada la relevancia de trabajar con recursos digitales en el aula. En vistas a ello, es imprescindible que los docentes exploren los diferentes materiales y géneros para potenciar los recursos de sus clases, los adecuen a las necesidades e intereses de los grupos y generen secuencias de actividades que favorezcan el desarrollo de los contenidos y habilidades propuestas. De este modo, la escuela no puede soslayar que las mediaciones tecnológicas revelan un potencial alternativo y habilitan múltiples formas -antes inimaginadas- de acceder a los textos orales. Así, la tecnología, en términos de Martín-Barbero (2009: 1) deja de ser mera una ayuda didáctica para convertirse en mediación cultural.

\section{Conclusiones}

No quedan dudas de que la irrupción de las nuevas tecnologías de la información y la comunicación expanden los modos de leer y escribir. Sobre la base ineludible de que la divulgación lectora y la experimentación en la producción escrita se potencian en las redes, el presente trabajo trazó un recorrido por los diferentes recursos virtuales que pueden contribuir con la enseñanza de la lengua y la literatura en el nivel medio, haciendo foco en los materiales producidos por los portales educativos y aquellos generados por especialistas.

Por un lado, el análisis mostró que el rol del docente se complejiza porque necesariamente ejerce como mediador entre sus estudiantes, la literatura, los libros impresos -a los que es necesario valorar y utilizar a la par- e internet. Los profesores se apropian de los recursos digitales y son ellos quienes los pueden transformar en materiales de enseñanza de acuerdo con los contenidos y los objetivos de enseñanza fijados en cada secuencia didáctica.

Por el otro, se logró demostrar el potencial de los recursos digitales para abordar la oralidad en el aula para la educación lingüística y literaria. En efecto, mediante el uso de recursos digitales, el docente puede instalar diversas situaciones comunicativas que requieran de la reflexión y el análisis de ciertos dispositivos -como el audiolibroy géneros orales -como el spot divulgativo o una presentación de un congreso-, en función de una escucha crítica y analítica.

Finalmente, si concebimos a la literatura como un campo del saber que posee su cuerpo de textos, sus formas de comunicar, construir y transmitir el conocimiento y sus formas de indagación, debemos pensar que, lejos de ser un ámbito estático, se encuentra en plena transformación.

En definitiva, el aula puede ser un espacio propicio para indagar sobre los géneros, formatos y comunidades lectoras actuales, así como para abordar los nuevos hábitos de lectura y escritura. Las formas de leer se encuentran en "ebullición" y podemos acceder a los textos mediante diferentes vías: leyendo, mirando, oyendo, vinculando, creando, escribiendo, recitando, dibujando, filmando y sintiendo. Si los medios digitales están preparando el camino para una revolución de la lectura (Chartier, 2015) y de la literatura (Goldsmith, 2015), entonces podemos pensar que el docente es quien podría acompañar a sus estudiantes en ese recorrido. 


\section{REFERENCIAS BIBLIOGRÁFICAS}

Adell, J. (2004). Internet en educación. Comunicación y Pedagogía, 200, 2528. Recuperado de http://elbonia.cent.uji.es/jordi/wp-content/uploads/docs/ Comunicacion_y_Pedagogia_def.pdf.

Andruetto, M. T. (2019). Discurso de cierre del Congreso de la Lengua. Córdoba: 30/03/2018. Recuperado de https://www.lavoz.com.ar/numero-cero/completomagistral-discurso-de-maria-teresa-andruetto-para-cierre-del-congreso-de-lengua.

Area Moreira, M. (2004). Los medios de enseñanza o materiales didácticos. Conceptualización y tipos. En M. Area Moreira, Los medios y las tecnologías en la educación (pp. 81-103). Madrid: Pirámide.

Chartier, R. (2015). Del códice a la pantalla: trayectorias de lo escrito. Cuaderno del Inadi, 11. Recuperado de http://cuadernos.inadi.gob.ar/numero-11/del-codice-ala-pantalla-trayectorias-de-lo-escrito/.

Dirección General de Cultura y Educación de la provincia de Buenos Aires (2010). Diseño curricular para la educación secundaria ciclo superior ES4: Literatura. Buenos Aires: DGC y E.

Goldsmith, K. (2015). Escritura no-creativa, gestionando el lenguaje en la era digital. Buenos Aires: Caja Negra.

Magadán, C. (2014). Enseñar lengua y literatura con las TIC. Buenos Aires: Cengaje Learning.

Marchetti, E. y Valente, A. (2016). The Many Voices of Audiobooks: Interactivity and Multimodality in Language Learning. En International Conference on Learning and Collaboration Technologies (pp. 165-176). Springer International Publishing.

Martín-Barbero, J. (2009). Cuando la tecnología deja de ser una ayuda didáctica para convertirse en mediación cultural. Revista Electrónica Teoría de la Educación. Educación y Cultura en la Sociedad de la Información, 10(1): 19-31.

Ministerio de Educación de la Nación (2015). Lecturas grabadas. Docentes. Buenos Aires: Ministerio de Educación.

Morales Sánchez, M. I. (2014). Enredos digitales. Los retos del lector ante la lectura y la escritura literarias en la red. En M. Campos Fernández-Fígares y E. Martos Núñez, Cartografías lectoras y otros estudios de lectura. La lectura en las universidades públicas andaluzas (pp. 177-187). Madrid: Marcial Pons.

Quiles Cabrera, M. C., Campos Fernández-Fígares, M. y Martos García, A. (2017). Poetas a pie de calle: espacios para la transferencia en la noche de los investigadores. @tic. revista de innovación educativa, 19: 40-46.

Quiles, M. C. (2016). La poesía, ¿ pasada de moda?: el lector infantil y juvenil entre el libro y el ciberespacio. EntreRíos. Revista de Arte y Letras, 25-26: 7-13.

Sáez, V. (2019). De las pantallas al papel. Nuevos acercamientos de los jóvenes a la 
literatura. Toldo de Astier. Propuestas y estudios sobre enseñanza de la lengua y la literatura, 10(18): 42-51.

Tosi, C. (2014). Políticas editoriales en el entorno digital. El caso de los materiales educativos. En Actas del I Jornadas Nacionales de Humanidades Digitales: Culturas, Tecnologías, Saberes, Buenos Aires, FFyL-UBA (pp. 197-210).

Tosi, C. (2015). El discurso de la crítica de la literatura infantil y juvenil. En Actas del Il Congreso de la delegación argentina de la Asociación de Lingüística y Filología de América Latina (ALFAL) y VII Jornadas Internacionales de Investigación en Lingüística y Filología, Universidad de La Plata.

Tosi, C. (2019). Marcas discursivas de la diversidad. Acerca del lenguaje no sexista y la educación lingüística: aproximaciones al caso argentino. Alabe, Revista de Investigación sobre Lectura y Escritura, 20. http://doi.org/10.15645/Alabe2019.20.11. 